\title{
Post-metabolic response to passive normobaric hypoxic exposure in sedendary overweight males: a pilot study
}

\author{
Chad Workman and Fabien A Basset ${ }^{*}$
}

\begin{abstract}
Background: The present pilot study was designed to test the impact of passive acute normobaric hypoxic exposure (PAH) and passive short-term normobaric hypoxic exposure (PSH) conditions on energy expenditure (EE) and substrates utilisation (glucose and lipid oxidation).

Methods: Eleven participants have completed the PAH session while the control group (CG) underwent a simulated experimental condition in normobaric normoxic condition. A subset of 6 participants underwent an additional six 3-hour sessions on consecutive days. Metabolic rates were obtained pre- and post-treatments on the morning following an overnight (12 hours) fast in PAH, PSH, and CG groups.

Results: The statistical outcomes showed a significant increase in EE for PAH, control, and PSH while a shift in substrate utilization towards lipid sources was only detected for PAH and PSH, respectively.

Conclusion: This pilot study showed that passive acute normobaric hypoxic exposure did affect EE and fuel utilization in sedentary overweight males and that further passive normobaric hypoxic exposures (PSH) magnified these metabolic adjustments. These outcomes provide valuable information for further research in the area of hypoxia as a new therapeutic strategy to improve the management of weight loss.
\end{abstract}

Keywords: Metabolic rate, Indirect calorimetry, Substrate partitioning, Hypoxia

\section{Background}

Obesity seriously threatens the public health in the westernized world [1]. Even though efforts have been made to reduce obesity, efficient solutions proposed from biological and behavioural sciences often do not appeal to all members of society as an effective means to reduce body fat. Obesity impairs physical performance and leads to an unfitness status that negatively affects whole body metabolism and daily energy expenditure [2].

Even though many scientific reports confirm the beneficial effects of regular physical activity on reduced mortality from all causes, including obesity, a mix of personal (e.g., past experience with exercise, health status), behavioural (e.g., skills), and environmental (e.g., access to facilities, type of program) factors influence both uptake and maintenance of exercise. In fact, most of the obese

\footnotetext{
* Correspondence: fbasset@mun.ca

School of Human Kinetics and Recreation, Memorial University of Newfoundland, St. John's, NL A1C 5S7, Canada
}

population in North America has a sedentary lifestyle, and approximately $60 \%$ of individuals who initiate an exercise program drop out within 3 to 6 months, well before any significant health benefits [3].

New perspectives have, however, emerged from studies on human hypoxic tolerance showing that some effects might be potentially beneficial in specific physiologic or pathologic conditions and could be an effective means to reduce body fat [4]. In fact, according to the most recent studies on the topic, moderately obese subjects did significantly lose weight after intermittent hypoxic exposures [5]. Hypoxia has also been associated with an augmented metabolic rate and an increase in energy expenditure [6], a general metabolic perturbation that might affect fuel utilization [7]. Previous studies have reported that the majority of weight loss in lean fit subjects was attributed to fat mass reduction, possibly due to increased fat oxidation [8-10].
C Biomed Central

(c) 2012 Basset and Workman; licensee BioMed Central Ltd. This is an Open Access article distributed under the terms of the Creative Commons Attribution License (http://creativecommons.org/licenses/by/2.0), which permits unrestricted use, distribution, and reproduction in any medium, provided the original work is properly cited. 
Yet, what effect low $\mathrm{O}_{2}$ concentration has on posthypoxic substrate metabolism is still not fully understood. One can postulate that hypoxia exposure triggers metabolic responses similar to, but not identical with, exercise-induced metabolic disruption [11]. If so, post hypoxic exposures (acute and short-term) might result in shifting substrate utilization towards lipid sources, due to the greater dependency on glucose under hypoxia [12]; a metabolic pattern that slightly differ from the excess post-exercise oxygen consumption concept and its related mechanisms [13].

To date, however, no study has examined the effect of passive acute and short-term hypoxic exposure on postmetabolic responses as related to substrate partitioning and energy expenditure. The present pilot study was, therefore, designed to test the impact of acute and short-term normobaric hypoxic exposure on substrate partitioning and energy expenditure. It was hypothesized that (a) acute normobaric hypoxic exposure would shift the fuel utilization towards lipid sources and would increase basal metabolic rate; (b) short-term normobaric hypoxic exposure would result in a cumulative effect on the above-mentioned metabolic responses.

\section{Methods}

\section{Participants}

Eleven sedentary overweight males - (BMI: $28 \pm 5 \mathrm{~kg} \bullet \mathrm{m}^{-2}$; height: $179 \pm 8 \mathrm{~cm}$; weight: $88 \pm 5 \mathrm{~kg}$ ) aged $28 \pm 3$ years old - participated in this study after having a medical examination. In addition, four sedentary overweight males (BMI: $27 \pm 2 \mathrm{~kg} \bullet \mathrm{m}^{-2}$; height: $173 \pm 12 \mathrm{~cm}$; weight: $82.2 \pm$ $11.5 \mathrm{~kg}$ ) aged $36 \pm 5$ years old - served as a control group. Participants were recruited from student population on Memorial University campus in response to advertisements posted on campus. They all filled in a Physical Activity Readiness Questionnaire (PAR-Q) to determine level of activity, and to screen for a history of any risk factor and health condition including smoking history, hypertension, cardio-respiratory disease, diabetes, musculoskeletal injuries or family history of any of the above-mentioned conditions in addition to known previous mountain sickness or altitude symptoms. They were excluded from the study if they took prescribed medication of any kind, were smokers or diagnosed as having; respiratory problems, heart disease, hypertension, chronic or acute illness, anxiety disorders, and drug or alcohol abuse. They were also excluded from the study if they were involved in any form of sports or structured exercise programs during the previous 12 months. The selected participants, then, attended an orientation session in which they were given information about the equipment and the experimental design, in addition to undergoing anthropometrics measurement. Finally, each participant signed a written informed consent in compliance with the declaration of Helsinki and with Memorial University's ethics committee regulations. Participants received one hundred dollar in compensation for their time and commitment as approved by the Human Investigation Committee.

\section{Experimental design}

Three sets of data were obtained from which two distinct groups underwent either a passive acute normobaric hypoxic exposure (PAH) consisting of a 3-hour normobaric hypoxic exposure or a passive short-term normobaric hypoxic exposure (PSH) consisting of 7 days of a single 3-hour normobaric hypoxic exposure session. The third set of data was obtained from the control group (CG). Participants were unaware of control or experimental conditions. Basal and post-treatment metabolic rates were measured on the first (day 1) and last day (day 7) of the experiment. During the treatment the oxygen concentration was maintained $\sim 80 \%$ blood $\mathrm{O}_{2}$ saturation $\left(\mathrm{S}_{\mathrm{p}} \mathrm{O}_{2}\right)$ as monitored by pulse oximetry. Food intake and physical activity were obtained from daily $\operatorname{logs}$ to estimate the total daily energy expenditure. All experimental sessions were conducted at the same time of the day. Eleven participants have completed $\mathrm{PAH}$ session while CG $(\mathrm{n}=4)$ underwent a simulated experimental condition in normobaric normoxic condition. A subset of 6 participants (BMI: $26 \pm 7 \mathrm{~kg} \cdot \mathrm{m}^{-2}$; height: $177 \pm 9 \mathrm{~cm}$; weight: $83 \pm 12 \mathrm{~kg}$ ) underwent an additional six 3-hour sessions (PSH) on consecutive days.

\section{Metabolic rate determination}

Participants were first subjected to a basal metabolic rate (BMR) and were, therefore, requested to comply with the following criteria prior to undergoing BMR: (1) to engage in no exercise during the preceding 36-hours; (2) to ingest no caffeine or alcohol during the preceding 24-hours; (3) to consume a last meal before 20:00 on the preceding evening and drink only water afterwards; (4) to travel to the laboratory by car or public transportation; (5) to rest for 30-min on a bed in a quiet environment prior to commencing recording metabolic data. Upon arrival to the laboratory, participants were placed in a comfortable, supine position in a quiet environment in preparation for metabolic rate measurement via indirect calorimetry technique. The participants were instructed to remain quiet and relaxed during data collection, but to stay awake. Upon the completion of treatment (experimental and control), participants underwent anew a metabolic rate measurement following the procedures described above.

\section{Experimental condition}

A modified generator, equipped with a semi permeable filtration membrane (nitrogen filter technique), continuously 
pumping air at a flow rate of $20 \mathrm{l} \cdot \mathrm{min}^{-1}$ into a facial mask lowered atmospheric $\mathrm{O}_{2}$ concentration to expose participants to an isometabolic stress, that is, the same relative $\mathrm{S}_{\mathrm{p}} \mathrm{O}_{2}(\sim 80 \%)$ during treatments $\left(\mathrm{GO}_{2}\right.$ Altitude, Biomedtech, Melbourne, Australia). Gas concentrations were monitored by oxygen sensor (Cambridge Sensotec, Cambs, UK). $\mathrm{S}_{\mathrm{p}} \mathrm{O}_{2}$ and heart rate (HR) were recorded online with a pulse oximeter $\left(\mathrm{GO}_{2}\right.$ Altitude, Biomedtech, Melbourne, Australia). In addition, blood pressure and acute mountain sickness inventory questionnaire were collected every 30-min over the course of exposure. During treatment and control sessions participants were allowed to perform sedentary tasks such as reading, writing, or television viewing. The session was stopped if blood pressure rose more than 30 systolic points from baseline, heart rate increase or decrease of more than 20 beats per minute from baseline or an increase in AMS score above 3 points.

\section{Cardio-respiratory measurements}

Oxygen uptake $\left(\dot{V} \mathrm{~V}_{2}, 1 \cdot \mathrm{min}^{-1}\right)$, carbon dioxide output $\left(\dot{V} C O_{2}, 1 \cdot \min ^{-1}\right)$, breathing frequency $\left(\mathrm{B}_{\mathrm{f}}\right)$ and tidal volume $\left(\mathrm{V}_{\mathrm{T}}\right)$ were continuously collected with an automated breath-by-breath system (Sensor Medics ${ }^{\circledR}$ version Vmax ST 1.0) using a nafion filter tube and a turbine flow meter (opto-electric). Minute ventilation and respiratory exchange ratio were calculated from $B_{f}$ and $V_{T}$, and from $\dot{V} \mathrm{O}_{2}$ and, $\dot{V} \mathrm{CO}_{2}$ respectively. Heart rate values were transmitted with a Polar heart rate monitor (PolarElectro, Kempele, Finland). The signal was transmitted to and recorded via the metabolic cart. Prior to testing, gas analyzers and volume were calibrated with medically certified calibration gases $\left(15 \% \mathrm{O}_{2}\right.$ and $\left.5 \% \mathrm{CO}_{2}\right)$ and with a 3-liter calibration syringe, respectively. In addition, to insure accurate calibration of the cart, the propane gas calibration was performed to assess the sensitivity of the oxygen and carbon dioxide analysers.

\section{Fuel selection}

Oxidation rates $\left(\mathrm{g} \cdot \mathrm{min}^{-1}\right)$ of carbohydrate $\left(\mathrm{CHO}_{\mathrm{ox}}\right)$ and lipid $\left(\mathrm{FAT}_{\mathrm{ox}}\right)$ were calculated according to the following equations [14]:

$$
\begin{aligned}
C_{\text {OX }}\left(g \mathrm{gmin}^{-1}\right)= & 4.59 \dot{V} \mathrm{CO}_{2}\left(\mathrm{~L} \mathrm{~min}^{-1}\right) \\
& -3.23 \dot{V} \mathrm{O}_{2}\left(\mathrm{~L} \mathrm{~min}^{-1}\right) \\
\text { FAT }_{O X}\left(g \mathrm{gmin}^{-1}\right)= & 1.70 \dot{V} \mathrm{VO}_{2}\left(\mathrm{~L} \mathrm{~min}^{-1}\right) \\
& +1.70 \dot{V} O_{2}\left(\mathrm{~L} \mathrm{~min}^{-1}\right)
\end{aligned}
$$

where $\dot{V} \mathrm{O}_{2}\left(1 \bullet \mathrm{min}^{-1}\right)$ and $\dot{V} C \mathrm{O}_{2}\left(1 \bullet \mathrm{min}^{-1}\right)$ were corrected for the volumes of $\mathrm{O}_{2}$ and $\mathrm{CO}_{2}$ corresponding to protein oxidation (1.010 and $0.843 \mathrm{l} \bullet^{-1}$, respectively). For relative contribution of substrates protein oxidation rate was estimated at $66 \mathrm{mg} \cdot \mathrm{min}^{-1}$ based on previously published urinary urea excretion measurements made on 12-h post-absorptive men with normal $\mathrm{CHO}$ reserves $[15,16]$.

Atmospheric conditions (atmospheric pressure, humidity, and temperature) were collected over the course of the study.

\section{Data reduction and analyses}

Pre- and post-exposure metabolic rates were truncated by 10 -min out of 30-min of data collection. The procedure discarded the first and last 5-min in order to nullify any metabolic rate fluctuation due to familiarisation with the facemask and the expected termination of data collection. The remaining 20-min segment was, then, integrated, normalized over time, converted in and expressed as energy expenditure (EE) in kilocalories (Kcal) and as oxidation of glucose and fat $\left(\mathrm{mg} \bullet \mathrm{min}^{-1}\right)$. The same truncation and integration were applied to $\mathrm{HR}, \mathrm{S}_{\mathrm{p}} \mathrm{O}_{2}$ pre- and post-exposure as well as during exposure.

\section{Statistical analyses}

All data are presented as mean and standard deviation unless otherwise specified. First, owing to unequal group sizes, paired t-tests were performed separately on $\mathrm{PAH}$ and CG to detect any significant change in EE and substrate partitioning. In addition, paired t-test was run on $\mathrm{S}_{\mathrm{p}} \mathrm{O}_{2}$ to insure that an isometabolic stress was applied on PAH during treatment. Second, a two-way ANOVA [2 periods (Pre and Post) x 6 epochs (30, 60, 90, 120, 150 , and 180-min)] with repeated measures on HR, and $\mathrm{BP}$ was computed to assess the effect of PAH. Third, a two-way ANOVA [2 periods (Pre and Post) x 2 time (day 1 and day 7)] with repeated measures on EE and substrate partitioning was run to detect the effect of $\mathrm{PSH}$, and on $\mathrm{S}_{\mathrm{p}} \mathrm{O}_{2}$ as for the previous condition. Finally, a three-way ANOVA [2 periods (Pre and Post) x 6 epochs $(30,60,90,120,150$, and 180-min) x 2 time (day 1 and day 7)] with repeated measures on $\mathrm{HR}$, and BP was computed to assess effect of treatment. Prior to running the statistical plans data sets were verified for normality (Wilk-Shapiro, Lilliefors, and KolmogorovSmirnov tests). As well, the assumption of sphericity was tested. When statistical significance was reached (alpha level of $p \leq 0.05$ ), post-hoc analyses were run to identify where significant mean differences occurred. The statistical Package for Social Sciences (SPSS, version 19) was used for all statistical analyses (SPSS Inc., Chicago, USA).

\section{Results}

\section{Environmental parameters}

Room temperature was maintained between 22 and $24^{\circ} \mathrm{C}$ throughout the experiment, while atmospheric conditions averaged between $99.5 \pm 0.6 \mathrm{kPa}$ and $86.0 \pm 10.7 \mathrm{Rh} \%$ 
at 7:30 and $99.6 \pm 0.5 \mathrm{kPa}$ and $73.4 \pm 15.0$ at 12:30 for barometric pressure and humidity, respectively.

\section{Health related parameters}

Based on the visual inspection of the acute mountain sickness score no statistical analysis was run. AMS scores ranged from 0 to 1 - with a minimum possible score of 0 and a maximum of 15 - confirming that participants did not experience any symptom of AMS. In addition, no participant has been removed from the experiment based on the criteria set by the experimenters such as blood pressure rising more than 30 systolic points from baseline, and/or a change of more than 20 beats $\cdot \mathrm{min}^{-1}$ in heart rate or an increase in AMS score above 3 points.

Although participants were required to record a daily diet and physical activity log, data obtained were insufficient for further analyses. However, from the questionnaire, the self-reported physical activity level of all applicants was below the Canadian guidelines for the general population.

\section{Cardiovascular parameters}

Descriptive statistics for $\mathrm{S}_{\mathrm{p}} \mathrm{O}_{2}, \mathrm{HR}$, and $\mathrm{BP}$ (systolic and diastolic) are presented in Table 1 . None of the abovelisted parameters did reach significance neither in $\mathrm{PAH}$ nor in PSH. As expected $\mathrm{S}_{\mathrm{p}} \mathrm{O}_{2}$ did not vary much - because it was monitored and controlled during treatment - as reflected by the coefficient of variation [CV $=3.5 \%$, $3 \%$, and $2.9 \%$ ] in $\mathrm{PAH}$ and $\mathrm{PSH}$, respectively. Although a large within-condition variability (on average: $\mathrm{SD} \pm 11.2$ ) was observed due to individual biological variance, the average $\mathrm{HR}$ in $\mathrm{PAH}$ and $\mathrm{PSH}$ did not vary much - by $6 \%$ at most. The systolic and diastolic pressures were affected neither in $\mathrm{PAH}$ nor in $\mathrm{PSH}$, the greatest variation reaching only $3 \%$ and $4 \%$ for SBP and DBP, respectively. For $\mathrm{CG}$ the average $\mathrm{HR}$ was $72 \pm 7$; unfortunately, the $\mathrm{S}_{\mathrm{p}} \mathrm{O}_{2}$ and $\mathrm{BP}$ were not recorded for this group.

\section{Energy expenditure}

The Figure 1 depicts the pre- to post-treatment variation in EE (PAH, CG, and PSH groups on the upper and

Table 1 Cardiorespiratory parameters for PAH and PSH

\begin{tabular}{|c|c|c|c|c|c|c|}
\hline \multirow{4}{*}{$\mathrm{S}_{\mathrm{p}} \mathrm{O}_{2}(\%)$} & \multirow{2}{*}{\multicolumn{2}{|c|}{$\frac{\mathrm{PAH}(\mathbf{n}=\mathbf{1 1})}{81 \pm 2}$}} & \multicolumn{4}{|c|}{ PSH $(n=6)$} \\
\hline & & & \multicolumn{2}{|c|}{$82 \pm 2$} & \multicolumn{2}{|c|}{$82 \pm 2$} \\
\hline & \multicolumn{2}{|c|}{ 3-hour exposure } & \multicolumn{2}{|c|}{ Day 1} & \multicolumn{2}{|c|}{ Day 7} \\
\hline & Pre & Post & Pre & Post & Pre & Post \\
\hline HR (beat•min ${ }^{-1}$ ) & $76 \pm 7$ & $83 \pm 6$ & $81 \pm 6$ & $89 \pm 6$ & $80 \pm 5$ & $85 \pm 11$ \\
\hline $\mathrm{SBP}(\mathrm{mmHg})$ & $116 \pm 8$ & $116 \pm 9$ & $114 \pm 9$ & $117 \pm 10$ & $114 \pm 9$ & $113 \pm 8$ \\
\hline $\mathrm{DBP}(\mathrm{mmHg})$ & $80 \pm 8$ & $78 \pm 8$ & $80 \pm 9$ & $80 \pm 9$ & $76 \pm 9$ & $79 \pm 6$ \\
\hline
\end{tabular}

Mean \pm SD.

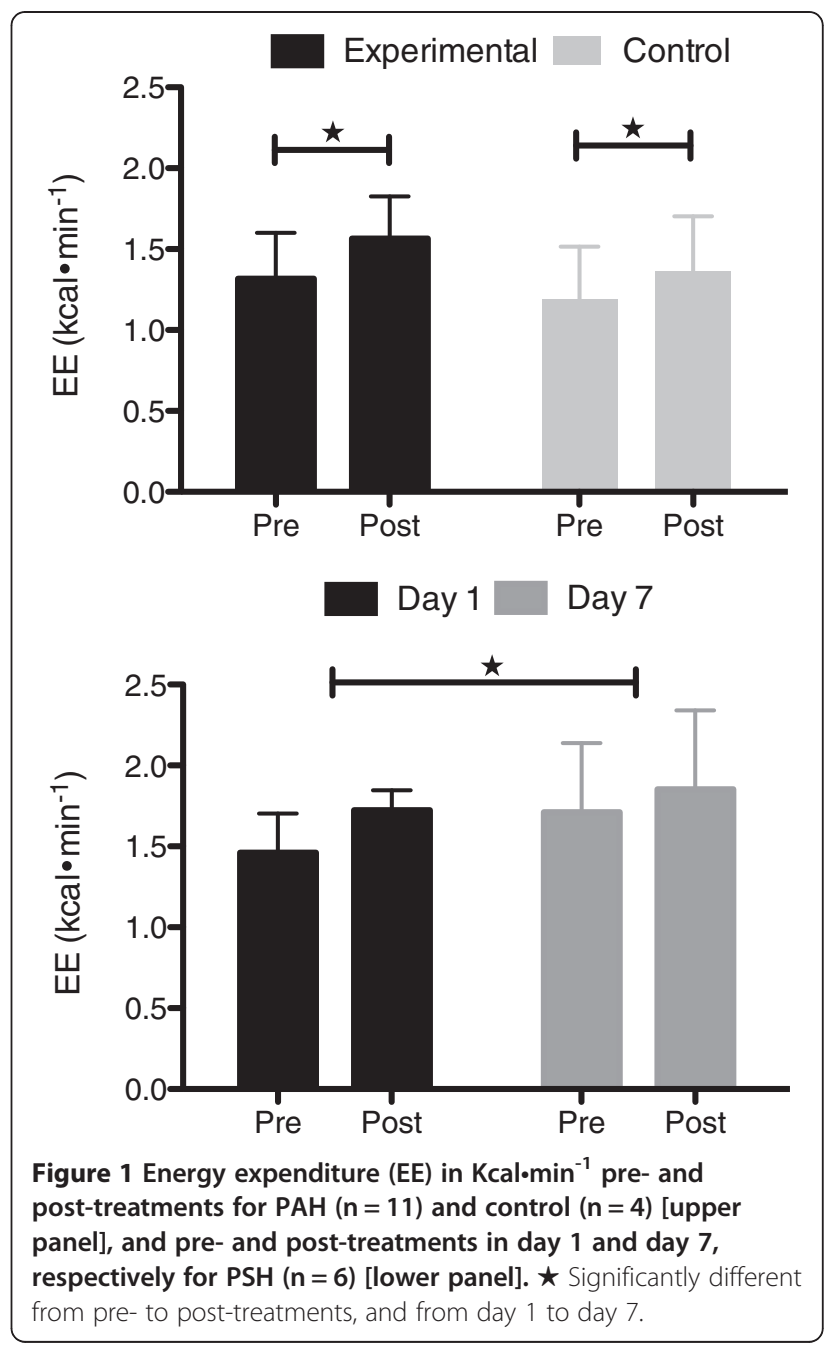

lower panel, respectively). The paired $t$-test outcomes revealed that EE significantly increased by $16 \%(p=0.002)$ and by $12.5 \%(p=0.029)$ for PAH and CG, respectively. The analysis of variance revealed that EE for PSH significantly differed from day 1 to day 7 increasing by $12 \%(p=0.037)$. However, it is worth noting that EE did increase by $18 \%$ on day 1 and continued to increase by $3 \%$ on day 7 .

\section{Fuel utilization}

Figure 2 depicts the substrate oxidation for PAH and CG, respectively. From the upper panel one can see that glucose oxidation significantly decreased by $31 \%(p=0.034)$ and fat oxidation significantly increased by $44 \%(p=0.001)$ from pre- to post-exposure. In comparison on lower panel CG increased glucose oxidation and slightly decreased fat oxidation by $35 \%$ and by $4 \%$, respectively but none of those scores did significantly differ from each other. Figure 3 (upper panel) showed that in PSH glucose oxidation, although not statistically significant, decreased from pre- to post-exposure by $34 \%(p=0.057)$, both days combined. 


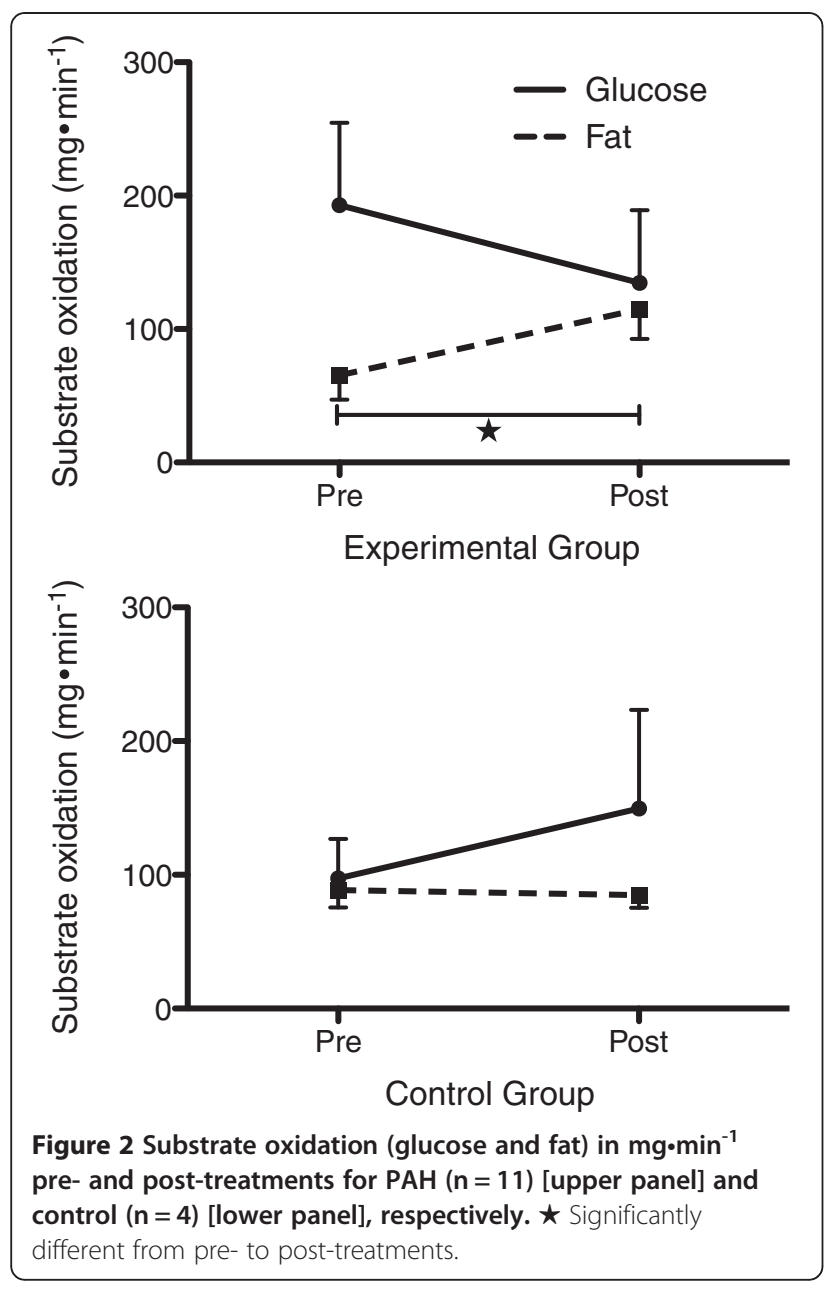

Glucose oxidation did decrease from pre- to post-exposure on day 1 by $26 \%$, and continued to decrease from pre- to post-exposure on day 7 by $49 \%$. In parallel and as displayed on Figure 3 (lower panel), fat oxidation significantly increased by $44 \%(p=0.006)$ from pre- to post-exposure and by $29 \%(p=0.05)$ from day 1 to day 7 .

\section{Discussion}

The purpose of this pilot study was to examine the effect of acute and short-term normobaric hypoxic exposure on post-metabolic responses. The novelty of the study resides in its experimental design. In fact, to the authors' best knowledge, it is the first time that a study was designed to record post-metabolic responses in normoxia immediately after being exposed to acute and short-term passive hypoxia. As postulated the outcomes showed a shift in substrate partitioning and an increase in energy expenditure in both acute and short-term conditions. Indeed, acute and short-term normobaric hypoxic exposures did lead to an increase in lipid oxidation and a decrease in glucose oxidation along with an augmented
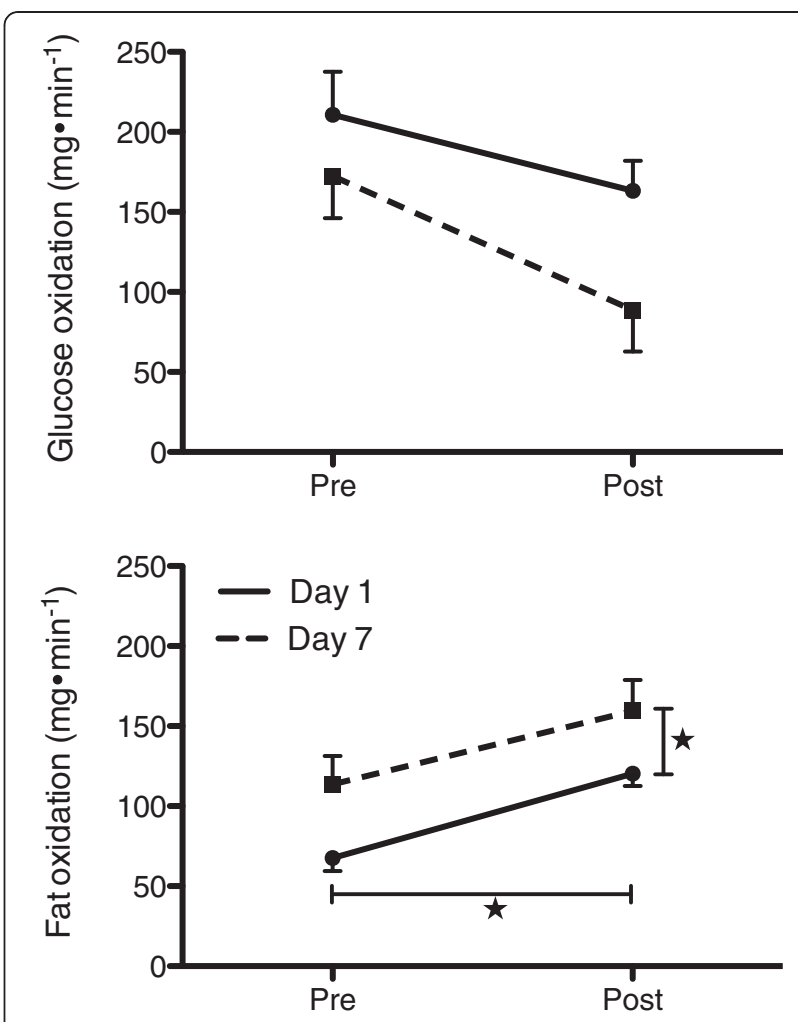

Figure 3 Fat oxidation [upper panel] and glucose oxidation [lower panel] in $\mathrm{mg} \cdot \mathrm{min}^{-1}$ pre- and post-treatments in day 1 and day 7 , respectively for PSH $(n=6)$. $\star$ Significantly different from pre- to post-treatments, and from day 1 to day 7 .

basal metabolic rate. The main outcomes of the investigation confirmed prior research reporting short-term hypoxic exposures to be of sufficient amplitude to initiate positive adaptive responses $[4,17]$.

\section{Cardiovascular parameters and health population characteristics}

As mentioned by Lippl et al. [18] most published studies have involved fit individuals or normal-weight participants rendering the interpretation quite difficult since confounding variable such as exercise, fitness and cold exposure might have interfered with altitude / hypoxic exposure. It has also been pointed out that acclimatory responses to hypoxia depend on the inter-individual variability, and training profile [19]. For instance, in highly trained athletes the extent to which performance improves could be too little to reach statistical significance [20] owing to optimization of their physiological systems (e.g., respiratory, cardiovascular, muscular). The data obtained, therefore, could barely be applied to unfit / sedentary obese subjects. In the current study, caution was made on selecting individuals with a $\mathrm{BMI}>25$ $\mathrm{kg} \cdot \mathrm{m}^{-2}$ who were not involved in any form of sports or structured exercise program during the previous 12 
months. Monitoring these parameters strengthened the effect of hypoxic exposure. In addition, the participants were submitted to a isometabolic stress, that is, $\mathrm{S}_{\mathrm{p}} \mathrm{O}_{2}$, was monitor and controlled during treatment to maintain oxygen desaturation around $82 \%$ at $2 \%$ of the initial target (80\%). The rationale underlying the isometabolic stress was to standardize as much as possible the environmental stimuli between subjects and to minimize the inter-subject variability. This may explain why none of the participants experienced acute mountain sickness event. No cardiovascular parameter was affected by the treatment neither in acute or short-term exposure. However, although none significant, heart rate was higher post- compared to pre-exposure values, a result that matched the higher significant $\mathrm{EE}$ observed in the present study as a consequence of the hypoxic treatment. It sounds then logical to observe an augmented cardiopulmonary function along with an increase metabolic rate since the cardiopulmonary system delivers the oxygen and substrate for replenishing stores [13].

\section{Energy expenditure}

Relatively brief periods of hypoxic exposure via a hypobaric chamber or inhalation of a normobaric hypoxic gas mixture stimulates erythropoietin [21] resulting in improved reticulocyte count, haemoglobin, and, haematocrit. These studies suggest that there is a good correlation between circulatory $\mathrm{O}_{2}$ transport and higher basal metabolic rate. Some authors have reported a significant increase in energy expenditure at least transiently at altitude or under hypobaric / normobaric hypoxia. For instance, Butterfield et al. [22] reported a significantly elevated BMR above sea level at the initial stage of a 21-day altitude stay whereas Mawson et al. [23] showed an increase in resting metabolic rate after 3 days of a 12-day altitude stay. Lastly, Lippl et al. [18] did show a significant increase in BMR after an altitude stay $(\sim 2650 \mathrm{~m})$ in sedentary obese people. Contrary to previous studies on the topic, the authors carefully controlled for the confounding factors, such as cold and physical activity. In the present study all groups did significantly increase EE from pre- to post-hypoxic exposure at rest and in a thermo-neutral condition. This result was partly explained by the transition from supine to seated position. However, there was a greater increase in EE in PAH compared to CG (16\% vs. $12.5 \%$ ) in addition to a carry-over effect from day one to day seven in PSH confirming that acute and short-term hypoxic exposure have had a greater effect than energy requirement of the seated position. The cumulative effect observed over the course of 7 days (12.5\% increase) corroborated previous studies showing an increase in basal metabolic rate following altitude stay [18,23-26]. The mechanisms behind the increase in EE at altitude / hypoxic exposure still remain debated. However,
Mawson et al. [23] and Louis et al. [27] have suggested that an increase in sympathetic nervous system activity might play a role.

\section{Fuel utilisation}

The main outcome of this pilot study showed that hypoxic exposures (acute and short-term) did affect substrate partitioning. The rationale underlying the current study was, based on the mechanisms contributing to the elevated post-exercise metabolism, that hypoxic exposure results in a general metabolic perturbation of which the repayment of the oxygen deficit may only contribute partially. LaForgia et al. [13] reported that the postexercise metabolic rate appears to be associated with higher lipid usage which is partially stimulated by increased catecholamine concentrations. The oxidation of lipid is known to contribute significantly to whole body energy turnover both at rest and during exercise $[28,29]$ and it is also greatly influenced by hypoxia. As recently reported, plasma levels of malondialdehydes (MDA), as determined by thiobarbituric acid reactive substances (TBARS), increased by $56 \%$ during exercise in hypoxia compared to normoxia, suggesting a shift towards lipid substrate [30]. This may reflect a greater autonomic neuroendocrine stimulation of lipolysis during hypoxia [31,32]. In fact, plasma epinephrine and norepinephrine levels significantly increased during hypoxic exercise compared to normoxic exercise [32,33] and still elevated post-exposure [33], indicating an additive effect of hypoxia on exercise. Our outcomes revealed that passive hypoxic exposure led to a significant shift in substrate utilization towards lipid sources in PAH and $\mathrm{PSH}$, respectively. Therefore passive hypoxic exposure is of sufficient amplitude to initiate acclimatory responses in sedentary people that may result in reduced body weight as previously shown in recent literature on the topic $[4,5]$. What effect low oxygen concentration has on post-hypoxic exposure metabolic systems related to weight loss is still not fully understood. Adaptive thermogenesis might be modified under hypobaric or normobaric hypoxia and could therefore be partially responsible for an impaired energy balance [34] and weight loss. However, the current results confirm that hypoxia modifies substrate metabolism in sedentary people and that might occur through alteration of the neuroendocrine system. For instance, adrenocorticotropic hormone (ACTH) induced steroidogenesis observed at rest and during exercise in hypoxia suggests that adrenal sensitivity for ACTH may be altered. In turn, it increases lipolytic responsiveness of adipocytes to catecholamines.

The effects of hypoxic exposure on substrate partitioning are still debated mainly because experimental designs used in the literature differ from one study to another [19]. Most of the studies that showed hypoxia induced 
insulin resistance and diminished glucose uptake $[27,35,36]$ was undergone with severe hypoxic gas mixture $\left(<10 \%\left[\mathrm{O}_{2}\right]\right)$. However, under more moderate hypoxic exposure $\left(>12 \%\left[\mathrm{O}_{2}\right]\right)$, a partial pressure of oxygen corresponding to 4000 metres of altitude and less, the metabolic response differs from the well-studied obstructive sleep apnea syndrome (OSAS) that leads to metabolic disruption [35]. For instance, Tonini et al. (2011) [37] observed in healthy participants a shift towards fat oxidation following 14 consecutive nights of intermittent hypoxia at $13 \%\left[\mathrm{O}_{2}\right]$. This somewhat surprising outcome was interpreted as a secondary consequence of reduced glucose uptake. According to these authors the availability of glucose or diminished glucose uptake induced by hypoxia causes the shift towards fat oxidation [38]. An alternative explanation could be that the increased sympathetic activity observed by Tamisier et al. (2011) [39] - same participants and same experimental design - might also explain the increased fat utilization. Repetitive severe intermittent hypoxic exposure as experienced by OSAS patients certainly leads to reduced insulin sensitivity over long periods of time [35]. However, short sessions of moderate hypoxic exposure as in the current study transiently affect fuel utilization, a positive metabolic response that resembles exercise-induced metabolic acclimation. Finally, one cannot discard that the difference between PAH and CG in the relative substrate contribution (see Table 2) might result in a distorted metabolic response owing to the very small sample size of 4 observations in the CG. However and as above-mentioned, the cumulative effect of hypoxic exposure showed that over time the substrate utilization did shift towards lipid sources to a greater magnitude compared to the acute condition and that, independently of CG metabolic response.

\section{Limitation of the study}

We acknowledge that the small sample size for the short-term condition might have affected the statistical power. However, we are very confident that the difference observed between the two conditions, which are at the heart of our discussion, is a true difference and not a type II error. In fact, the observed statistical power for glucose and lipid in PSH are 0.512 and 0.946 , respectively. Another limitation relates to the sample size of the control group consisting of only four individuals. However, this group has been implemented to monitor for any fasting effect on the dependent variables $[40,41]$ rather than a true control group as above-mentioned. Although the lack of biological markers related to the substrate metabolism can be viewed as a possible shortcoming, the indirect calorimetry technique has been used extensively to measure energy expenditure and substrate partitioning from respiratory gas exchanges $[14,42,43]$ and has been proven to be a reliable and valid technique of metabolic measurement, especially at rest [44]. In addition, in this study particular caution was taken on calibration technique. Indeed, we did use the propane gas technique to calibrate the metabolic cart for very low metabolic responses. A final point that must be mentioned relates to the daily food intake log. A daily log would have provided an informative summary on participants' food habit but data obtained from the logs were insufficient for further analyses. We are, however, confident that all participants did strictly comply with the five criteria associated with basal metabolic rate determination, a procedure that nullified the potential effect of diet.

\section{Potential clinical applications}

If the present results are confirmed, it will lead to a new non-pharmacological strategy for the treatment of obesity. In fact, the dramatic increase in obesity worldwide being a serious threat to public health hypoxic exposure might offer a new therapeutic strategy to improve the management of weight loss. Higher aerobic pathway efficiency will lead to an increase in basal metabolic rate and daily energy expenditure. Hypoxia could, then, reverse the inefficient oxidative capacity of the obese muscle and cause weight loss.

\section{Conclusion}

The present experiment aimed at examining the role of short-term normobaric hypoxic exposure on oxidative processes. The experimental design did evaluate and compare the efficacy of hypoxic exposures that brings

Table 2 Relative contribution of substrates

\begin{tabular}{|c|c|c|c|c|c|c|c|c|}
\hline & \multicolumn{4}{|c|}{ Acute } & \multicolumn{4}{|c|}{ Short-term } \\
\hline & \multicolumn{2}{|c|}{ Experimental $(n=11)$} & \multicolumn{2}{|c|}{ Control $(n=4)$} & \multicolumn{2}{|c|}{ Day one $(n=6)$} & \multicolumn{2}{|c|}{ Day Seven $(n=6)$} \\
\hline & Pre & Post & Pre & Post & Pre & Post & Pre & Post \\
\hline Glucose & $58 \pm 2$ & $45 \pm 2$ & $38 \pm 2$ & $45 \pm 3$ & $54 \pm 4$ & $51 \pm 3$ & $44 \pm 2$ & $25 \pm 3$ \\
\hline Lipid & $21 \pm 1$ & $34 \pm 1$ & $35 \pm 2$ & $31 \pm 2$ & $25 \pm 4$ & $31 \pm 2$ & $31 \pm 2$ & $46 \pm 3$ \\
\hline Protein & $21 \pm 1$ & $21 \pm 1$ & $27 \pm 1$ & $23 \pm 2$ & $21 \pm 1$ & $18 \pm 1$ & $17 \pm 1$ & $19 \pm 1$ \\
\hline
\end{tabular}

Mean \pm SEM.

Protein oxidation rate was estimated at $66 \mathrm{mg} \cdot \mathrm{min}^{-1}$. 
global systemic physiological changes. The main results of the study confirmed that in overweight people acute and short-term normobaric hypoxia increase metabolic rate and shift substrate utilization towards lipid sources.

\section{Abbreviations}

BMI: Body mass index; BMR: Basal metabolic rate; BP: Blood pressure; CG: Control group; $\mathrm{CHO}_{\text {ox: }}$ Glucose oxidation; EE: Energy expenditure; FAT ox: Fat oxidation; HR: Heart rate; Kcal: Kilocalorie; PAH: Passive acute hypoxia; PAR-Q: Physical activity readiness questionnaire; PSH: Passive shortterm hypoxia; $\mathrm{S}_{\mathrm{p}} \mathrm{O}_{2}$ : blood $\mathrm{O}_{2}$ saturation; $\mathrm{V} \mathrm{CO}_{2}$ : Volume of carbon dioxide; $\dot{\mathrm{V}} \mathrm{O}_{2}$ : Volume of oxygen.

\section{Competing interests}

The authors insure that they have no conflict of interest of any kind.

\section{Authors' contributions}

Both authors have equally contributed to the design of the study, the data collection and analysis, data interpretation and manuscript writing. All authors read and approved the final manuscript.

\section{Acknowledgements}

We gratefully acknowledge Jessica Rideout for her technical support, and the subjects for their participation and devotion to this work. This project was funded by Newfoundland and Labrador Centre for Applied Health Research and by the School of Human Kinetics and Recreation, Memorial University of Newfoundland.

Received: 27 August 2012 Accepted: 3 November 2012

Published: 16 November 2012

\section{References}

1. Azagury DE, Lautz DB: Obesity overview: epidemiology, health and financial impact, and guidelines for qualification for surgical therapy. Gastrointest Endosc Clin N Am 2011, 21:189-201.

2. Menshikova EV, Ritov VB, Toledo FG, Ferrell RE, Goodpaster BH, Kelley DE: Effects of weight loss and physical activity on skeletal muscle mitochondrial function in obesity. Am J Physiol 2005, 288:818-825.

3. Basset FA: Fighting the obesity epidemic. In Down Home. 44th edition. 2008:72-73.

4. Bernardi L: Interval hypoxic training. Adv Exp Med Biol 2001, 502:377-399.

5. Terao T, Miyakawa C, Yamanami Y, Saito M: The effects of walking exercise in hypobaric and normobaric environments on resting metabolic rate and body composition in obese adults. Osterreichisches Journal fur Sportmedizin 2003, 33:26-31.

6. Nair CS, Malhotra MS, Gopinath PM: Effect of altitude and cold acclimatisation on the basal metabolism in man. Aerosp Med 1971, 42:1056-1059.

7. Shatilo VB, Korkushko OV, Ischuk VA, Downey HF, Serebrovskaya TV: Effects of intermittent hypoxia training on exercise performance, hemodynamics, and ventilation in healthy senior men. High Alt Med Biol 2008, 9:43-52.

8. Westerterp KR, Kayser B: Body mass regulation at altitude. Eur J Gastroenterol Hepatol 2006, 18:1-3.

9. Westerterp KR, Meijer EP, Rubbens M, Robach P, Richalet JP: Operation Everest III: energy and water balance. Pflugers Arch. 2000, 439:483-488.

10. Westerterp-Plantenga MS: Effects of extreme environments on food intake in human subjects. Proc Nutr Soc 1999, 58:791-798.

11. Hochachka PW, Gunga HC, Kirsch K: Our ancestral physiological phenotype: an adaptation for hypoxia tolerance and for endurance performance? Proc Natl Acad Sci USA 1998, 95:1915-1920.

12. Braun B: Effects of high altitude on substrate use and metabolic economy: cause and effect? Med Sci Sports Exerc 2008, 40:1495-1500.

13. LaForgia J, Withers RT, Gore CJ: Effects of exercise intensity and duration on the excess post-exercise oxygen consumption. J Sports Sci 2006 24:1247-1264.

14. Ferrannini E: The theoretical bases of indirect calorimetry: a review. Metab Clin Exp 1988, 37:287-301.
15. Haman F, Peronnet F, Kenny GP, Massicotte D, Lavoie C, Scott C, Weber JM: Effect of cold exposure on fuel utilization in humans: plasma glucose muscle glycogen, and lipids. J App/ Physio/ 2002, 93:77-84

16. Haman F, Legault SR, Weber JM: Fuel selection during intense shivering in humans: EMG pattern reflects carbohydrate oxidation. J Physiol 2004, 556:305-313.

17. Clanton TL, Klawitter PF: Invited review: Adaptive responses of skeletal muscle to intermittent hypoxia: the known and the unknown. J Appl Physiol 2001, 90:2476-2487.

18. Lippl FJ, Neubauer S, Schipfer S, Lichter N, Tufman A, Otto B, Fischer R: Hypobaric hypoxia causes body weight reduction in obese subjects. Obesity 2010, 18:675-681.

19. Basset FA, Joanisse DR, Boivin F, St-Onge J, Billaut F, Dore J, Chouinard R, Falgairette G, Richard D, Boulay MR: Effects of short-term normobaric hypoxia on haematology, muscle phenotypes and physical performance in highly trained athletes. Exp Physiol 2006, 91:391-402.

20. Hopkins WG, Hawley JA, Burke LM: Design and analysis of research on sport performance enhancement. Med Sci Sports Exerc 1999, 31:472-485.

21. Wilber RL: Current trends in altitude training. Sports Med 2001, 31:249265.

22. Butterfield GE, Gates J, Fleming S, Brooks GA, Sutton JR, Reeves JT: Increased energy intake minimizes weight loss in men at high altitude. J Appl Physiol 1992, 72:1741-1748.

23. Mawson JT, Braun B, Rock PB, Moore LG, Mazzeo R, Butterfield GE: Women at altitude: energy requirement at 4,300 m. J Appl Physio/ 2000, 88:272-281

24. Picon-Reategui E: Basal metabolic rate and body composition at high altitudes. J App/ Physiol 1961, 16:431-434

25. Picon-Reategui E, Lozano R, Valdivieso J: Body composition at sea level and high altitudes. J App/ Physiol 1961, 16:589-592.

26. Nair CS, Malhotra MS, Tiwari OP, Gopinath PM: Effect of altitude acclimatisation and cold on cold pressor response in man. Aerosp Med 1971, 42:991-994.

27. Louis M, Punjabi NM: Effects of acute intermittent hypoxia on glucose metabolism in awake healthy volunteers. J App/ Physiol 2009, 106:1538-1544.

28. Kiens B, Richter EA: Utilization of skeletal muscle triacylglycerol during postexercise recovery in humans. Am J Physiol 1998, 275:E332-E337.

29. Sahlin K, Harris RC: Control of lipid oxidation during exercise: role of energy state and mitochondrial factors. Acta Physiol (Oxf) 2008, 194:283-291.

30. Pialoux V, Mounier R, Ponsot E, Rock E, Mazur A, Dufour S, Richard R, Richalet JP, Coudert J, Fellmann N: Effects of exercise and training in hypoxia on antioxidant/pro-oxidant balance. Eur J Clin Nutr 2006, 60:1345-1354

31. Barnholt KE, Hoffman AR, Rock PB, Muza SR, Fulco CS, Braun B, Holloway L, Mazzeo RS, Cymerman A, Friedlander AL: Endocrine responses to acute and chronic high-altitude exposure (4,300 meters): modulating effects of caloric restriction. Am J Physiol 2006, 290:E1078-E1088.

32. Kjaer M, Bangsbo J, Lortie G, Galbo H: Hormonal response to exercise in humans: influence of hypoxia and physical training. Am J Physiol 1988, 254:R197-R203.

33. Strobel $G$, Neureither $M$, Bartsch P: Effect of acute mild hypoxia during exercise on plasma free and sulphoconjugated catecholamines. Eur J Appl Physiol Occup Physiol 1996, 73:82-87.

34. Tschop M, Morrison KM: Weight loss at high altitude. In Hypoxia: from genes to the bedside. Volume 502. Edited by Roach RC, Wagner PD, Hackett $\mathrm{PH}$. New York: Kluwer Academic/Plenum Publishers; 2001:445. Advances in experimental medicine and biology.

35. O'Donnell CP: Metabolic consequences of intermittent hypoxia. Adv Exp Med Biol 2007, 618:41-49.

36. Polotsky WY, Li J, Punjabi NM, Rubin AE, Smith PL, Schwartz AR, O'Donnell CP: Intermittent hypoxia increases insulin resistance in genetically obese mice. J Physiol 2003, 552:253-264

37. Tonini J, Michallet AS, Flore P, Nespoulet H, Pepin JL, Wuyam B, Levy P, Tamisier R: Effect of chronic intermittent hypoxia on exercise adaptations in healthy subjects. Respir Physiol Neurobiol 2011, 179:287-293.

38. Sidossis LS, Wolfe RR: Glucose and insulin-induced inhibition of fatty acid oxidation: the glucose-fatty acid cycle reversed. Am J Physiol 1996, 270:E733-E738. 
39. Tamisier R, Pepin JL, Remy J, Baguet JP, Taylor JA, Weiss JW, Levy P: 14 nights of intermittent hypoxia elevate daytime blood pressure and sympathetic activity in healthy humans. Eur Respir J 2011, 37:119-128.

40. Poehlman ET, Arciero PJ, Melby CL, Badylak SF: Resting metabolic rate and postprandial thermogenesis in vegetarians and nonvegetarians. Am J Clin Nutr 1988, 48:209-213.

41. Zinker BA, Britz K, Brooks GA: Effects of a 36-hour fast on human endurance and substrate utilization. J Appl Physiol 1990, 69:1849-1855.

42. Tappy L, Schneiter P: Measurement of substrate oxidation in man. Diabetes Metab 1997, 23:435-442.

43. Simonson DC, DeFronzo RA: Indirect calorimetry: methodological and interpretative problems. Am J Physiol 1990, 258:E399-E412.

44. Lighton JR: Measuring metabolic rates: a manual for scientists. New York: Oxford University Press; 2008

doi:10.1186/1743-7075-9-103

Cite this article as: Workman and Basset: Post-metabolic response to passive normobaric hypoxic exposure in sedendary overweight males: a pilot study. Nutrition \& Metabolism 2012 9:103.

\section{Submit your next manuscript to BioMed Central and take full advantage of:}

- Convenient online submission

- Thorough peer review

- No space constraints or color figure charges

- Immediate publication on acceptance

- Inclusion in PubMed, CAS, Scopus and Google Scholar

- Research which is freely available for redistribution 